\title{
Magmatic sill formation during dike opening
}

\author{
Zhonglan. Liu, and W. Roger. Buck \\ Correspondence to: zliu@marum.de
}

\section{This PDF file includes:}

Supplementary Text section S1 | Temperature and rheology setups

Supplementary Text section S2 | Adaptive boundary condition for simulating dike opening

Supplementary Text section S3 | Alternative thermal structures and multiple dike events

Supplementary Text section S4 | Plane strain changes in stress on dike opening

Supplementary Figure S1 | Viscosity of the reference model

Supplementary Figure S2 $\mid$ Comparison between $\boldsymbol{P}_{\boldsymbol{m}}-\boldsymbol{\sigma}_{v}$ and horizontal deviatoric stress

Supplementary Figure S3 | Cases with different geothermal gradients

Supplementary Figure S4 | Case with uniform lithospheric thickness

Supplementary Figure S5 | Model results for two loading and dike-opening periods 


\section{S1. Temperature and rheology setups}

We specify a fixed temperature field that controls the rheologic structure of an idealized spreading center. Temperature variations with depth are piecewise linear with the surface of the model domain kept at $0^{\circ} \mathrm{C}$. A uniform gradient from $0^{\circ} \mathrm{C}$ to $600^{\circ} \mathrm{C}$ was set by the depth of the $600^{\circ} \mathrm{C}$ isotherm. The temperature gradient in the region deeper than the $600^{\circ} \mathrm{C}$ isotherm is 2.5 times that of the shallow part. The maximum temperature is set to $1300^{\circ} \mathrm{C}$. The depth to the $600^{\circ} \mathrm{C}$ isotherm is defined by Gaussian shape with a half width of $3.5 \mathrm{~km}$ and a maximum depth of $6 \mathrm{~km}$ (Fig.S1). The axial depth of the $600^{\circ} \mathrm{C}$ isotherm varies from 0.5 to $2.5 \mathrm{~km}$ in different models. This setting is a reasonable proxy for the temperature structure of fast midocean ridges inferred from seismic data (Dunn et al., 2000) and commonly used when considering thermal structure at fast mid-ocean ridges (Buck et al., 2005). Different temperature structure settings do not affect the main conclusions of this work as shown in Figures S3 and S4.

The rheology of the model domain is Maxwell viscoelastic. Since we are concerned with oceanic crust, rheologic parameters consistent with measurements of diabase are considered. Elastic behavior is taken to be isotropic and described by a shear modulus, $G$, set to $30 \mathrm{GPa}$ (Birch, 1966) and the Poisson's ratio (v) is set to 0.25 . The viscosity in our model is taken to depend on strain rate $\dot{\varepsilon}$ and inverse temperature, as:

$\eta=A^{\frac{-1}{n}} \dot{\varepsilon}^{\frac{1-n}{n}} \exp \left(\frac{Q}{n R T}\right)$

where $A$ is the pre-factor, $Q$ is the activation energy, $R$ is the gas constant and $T$ is the absolute temperature. Based on the rheological properties of dry diabase (Mackwell et al., 1998), $A$ is set to $0.125(\mathrm{~Pa} \mathrm{~s})^{1 / \mathrm{n}}, n$ is 3.05 , and $Q$ is $276 \mathrm{k} \mathrm{J} / \mathrm{mol}$. We set any region with a temperature greater than $1100^{\circ} \mathrm{C}$ to the minimum viscosity, $\eta_{\min }$ as shown in Figure $\mathrm{S} 1$. 


\section{S2. Adaptive boundary condition for simulating dike opening}

The boundary condition for dike opening is that the horizontal stress in the lithosphere adjacent to the dike equals the magma pressure in the dike. In some studies (e.g., Qin and Buck, 2008) this is done by specifying the normal stress on the left boundary from the surface to a specified trial depth and calculating the resulting opening. Since the opening of the dike produces relative tension in the sub-lithospheric region this approach requires iterating on the depth of the base of the dike until deepening the dike does not produce opening at the trial depth.

To obviate iteration on the maximum opening depth we formulated the left boundary condition during dike opening in terms of a velocity boundary condition that depends on the different between magma pressure and horizontal stress. Dike opening is an elastically driven process and if magma is instantly supplied the opening should happen in a matter of seconds. However, viscous flow in an opening dike should slow the process. To illustrate this and show how stresses evolve during dike opening, we slowed the opening of the dike. The velocity of half-dike opening, $U^{\text {dike }}$ is set to be:

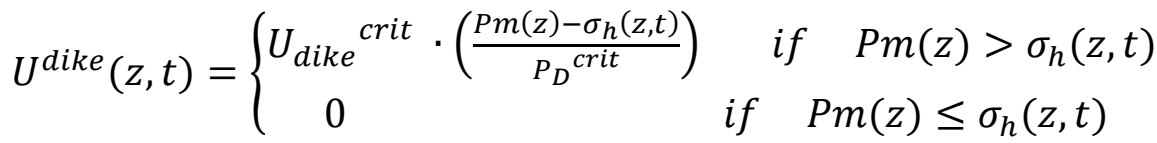

Where $z$ is depth, $t$ is numerical time and $U_{\text {dike }}{ }^{\text {crit }}$ is a critical dike opening rate, assumed to be $1 \mathrm{~m}$ /hour. $P m$ is magma pressure, $\sigma_{h}$ is horizontal stress in the crust and $P_{D}{ }^{\text {crit }}$ is a critical driving pressure of dike opening, which is set to $10 \mathrm{MPa}$. With this approach the dikes gradually opens deeper as the axial horizontal stresses adjacent to the open dike approach the magma pressure in the dike as shown in Figure 2 of the main text. 


\section{S3. Alternative thermal structures and multiple dike events}

In Figure S3, we show the influence of different geothermal gradients on post-dike stresses. The results indicate that a high geothermal gradient below $600^{\circ} \mathrm{C}$ isotherm favors the formation of magmatic sills. A case with uniform lithospheric thickness with distance from the spreading axis that produces conditions favorable for sill opening is shown is Figure S4. Figure S5 shows that multiple loading and dike-opening periods can still result in magma pressure that are greater than the dike-induced vertical stresses.

\section{S4. Plane strain changes in stress on dike opeing}

To better understand the stress changes induced by dike opening we consider what affects the vertical stresses close to an opeing dike. Our model uses the plane strain approximation (P.136 of Turcotte and Schubert., 2014) and given that we assume a Poisson's Ratio of 0.25 this allows us to estimate the changes in vertical stress due to vertical displacements and horizontal stress changes as:

$\Delta \sigma_{V}=\frac{8 G}{3} \varepsilon_{v}+\frac{1}{3} \Delta \sigma_{H}$

where $G$ is the Shear Modulus, $\varepsilon_{v}$ the vertical strain and $\Delta \sigma_{H}$ is the horizontal stress change. Clearly the vertical stress is very sensitive to vertical strains and the uplift of the surface seen in our models shows that those strains are extensional. Any increase in horizontal stress (i.e. compression give the geologic stress convention) causes vertical compression.

Equation S3 offers an explanation of the role of sub-lithospheric viscosity in the dike induced vertical stress changes. If that viscosity is high (or the related Maxwell Time is long) the horizontal extensional stresses related to plate spreading are not reduced by viscous relaxation. Where pre-dike opening horizontal stresses are smaller than the magma pressure the opening of a dike causes horizontal compression. This contributes vertical compression that counters the vertical extensional stresses produced by vertical extensional strain. 


\section{References:}

Birch, F., 1966, Compressibility; elastic constants: Handbook of physical constants, p. 97-173.

Buck, W. R., Lavier, L. L., \& Poliakov, A. N. 2005, Modes of faulting at mid-ocean ridges. Nature, 434(7034), 719-723.

Dunn, R. A., Toomey, D. R., and Solomon, S. C., 2000, Three-dimensional seismic structure and physical properties of the crust and shallow mantle beneath the East Pacific Rise at 9 30'N: Journal of Geophysical Research: Solid Earth, v. 105, no. B10, p. 2353723555.

Mackwell, S., Zimmerman, M., and Kohlstedt, D., 1998, High-temperature deformation of dry diabase with application to tectonics on Venus: Journal of Geophysical Research: Solid Earth, v. 103, no. B1, p. 975-984.

Purdy, G., Kong, L., Christeson, G., and Solomon, S., 1992, Relationship between spreading rate and the seismic structure of mid-ocean ridges: Nature, v. 355 , no. 6363 , p. $815-$ 817.

Turcotte, D. L., \& Schubert, G. 2014. Geodynamics ( $3^{\text {rd }}$ ed.). Cambridge University Press. 


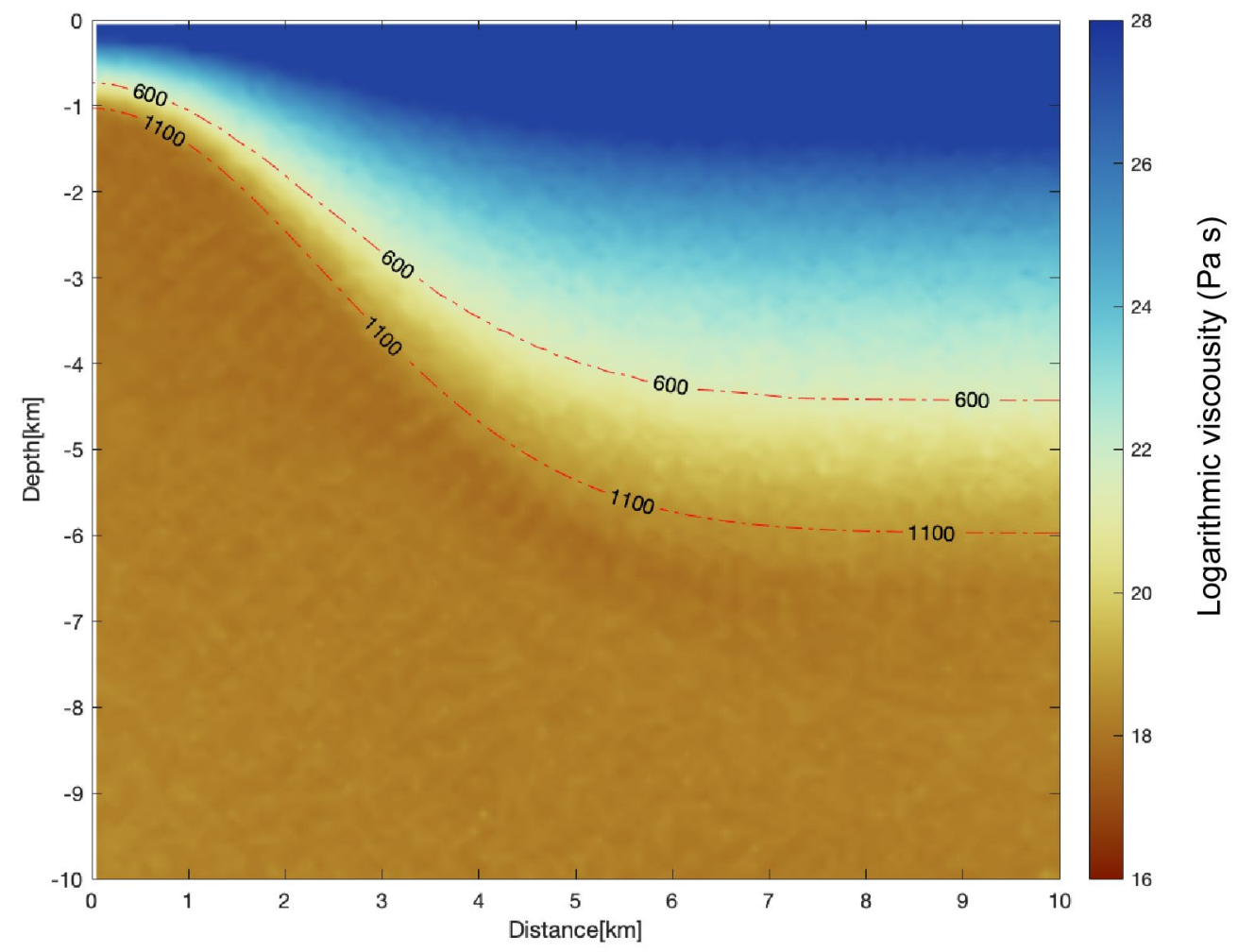

Figrue S1. Viscosity of the reference model. The red lines represents the indicated isotherms that have a Gaussian shape with distance form the spreading axis. Refernce model results are shown in Figure 2 of the main text. 
(a) Horizontal deviatoric stress [Mpa]

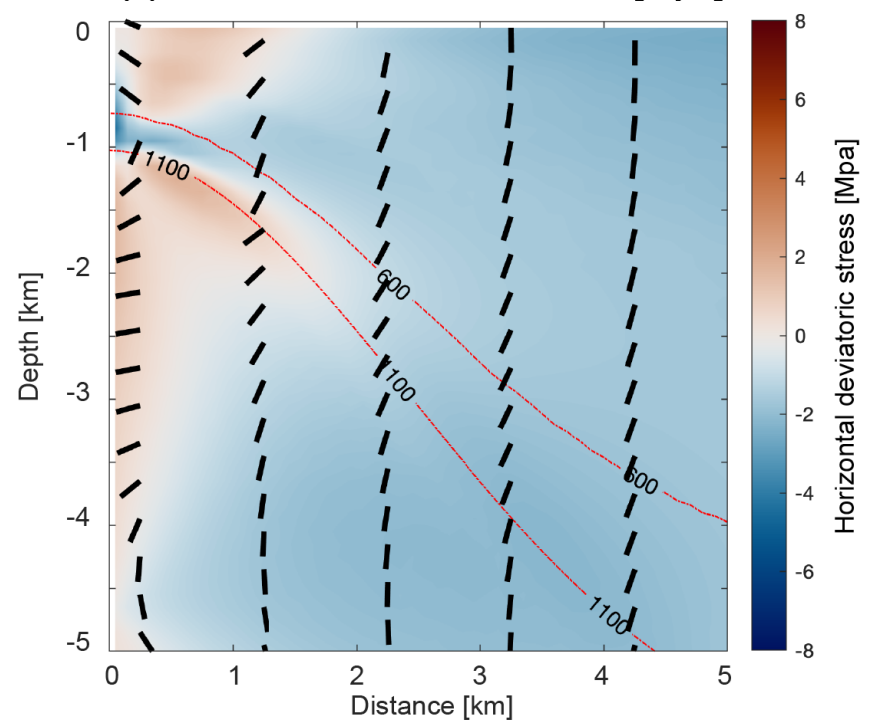

(b) Pm- $\sigma_{v}[\mathrm{Mpa}]$

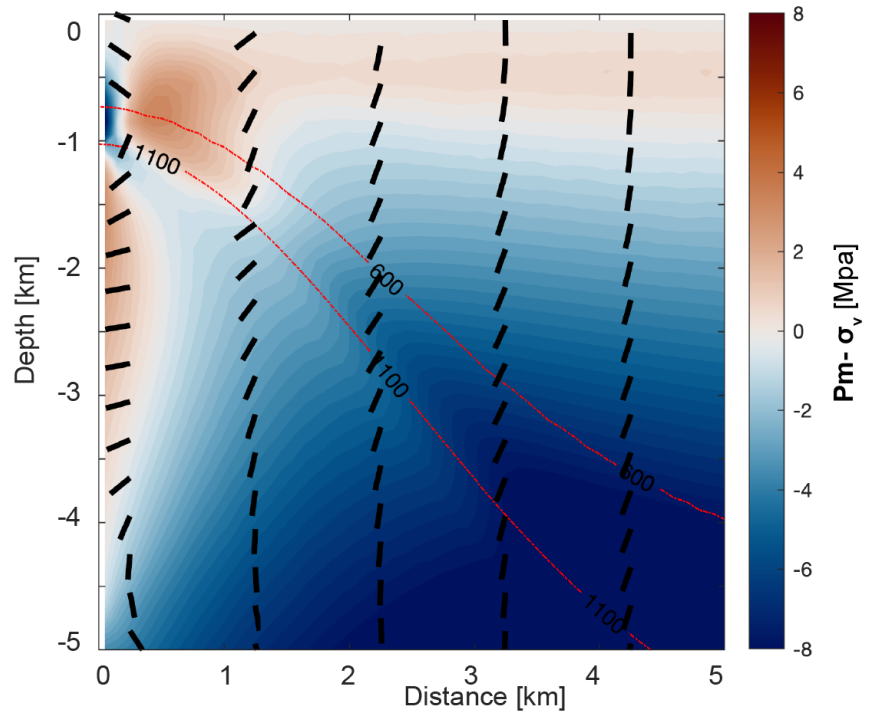

Figure S2. Comparison between $P_{m}-\sigma_{v}$ and horizontal deviatoric stress. (a) Horizontal deviatoric stress after a dike opens and (b) is showing magma pressure $(P m)$ - vertical stress $\left(\sigma_{v}\right)$. Refernce model results are shown in Figure 2 of the main text. 
(a) Geotherm ductile $_{\text {G }}$ Geotherm brittle $=5$

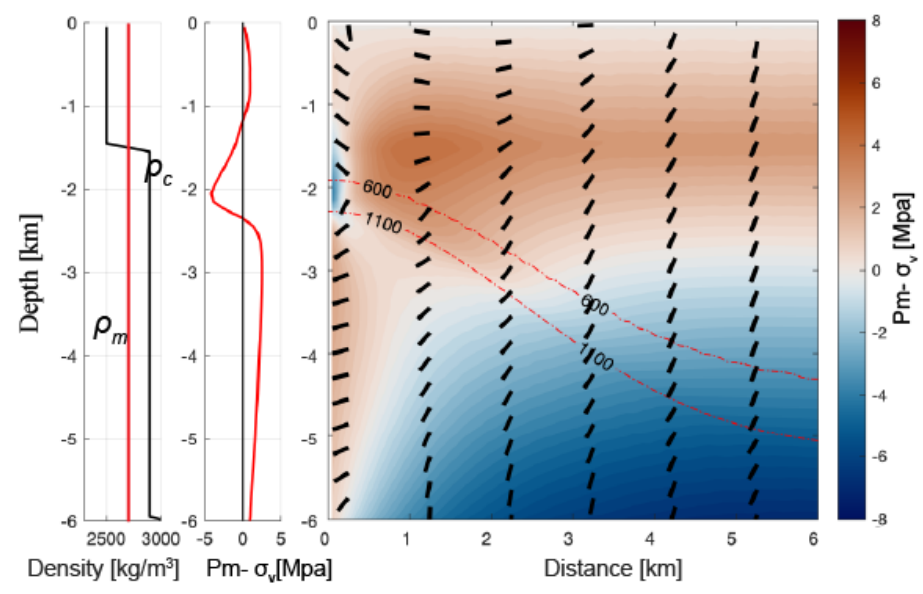

(b) Geotherm ductile $/$ Geotherm $_{\text {brittle }}=2.5$

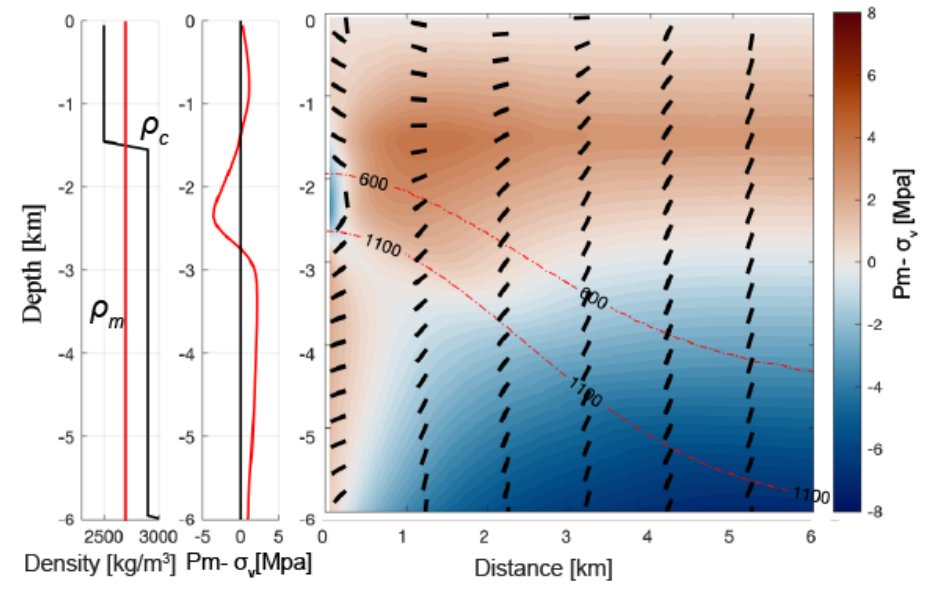

(c) Geotherm ductile $/$ Geotherm $_{\text {brittle }}=1$

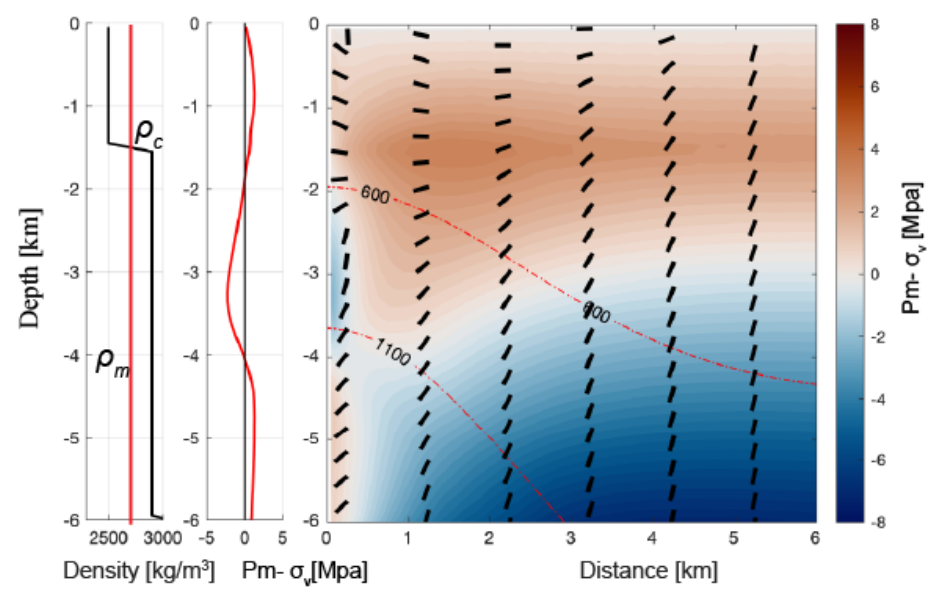

Figure S3. Cases with different geothermal gradients. Post-dike opeing model stresses for different geothermal gradients (Geotherm ductile) of the ductile layer with the same setup as the reference model shown in Figure 2 of the main text. The ductile layer is defined to be. between the 600 and $1100^{\circ}$ isotherms. The greater the ratio of the geothermal gradient in the ductile layer to that in the brittle layer (Geotherm brittle), the more favorable the sub-lithospheric stresses for the formation of sills. $\rho_{m}$ is the density of magma and $\rho_{c}$ is crustal density. The panel shows the distribution of the difference between the reference magma pressure and the vertical stress. Black lines show the orientation of maximum stress and the red dashed lines represent isotherms. 
Influence of the lateral geothermal structure
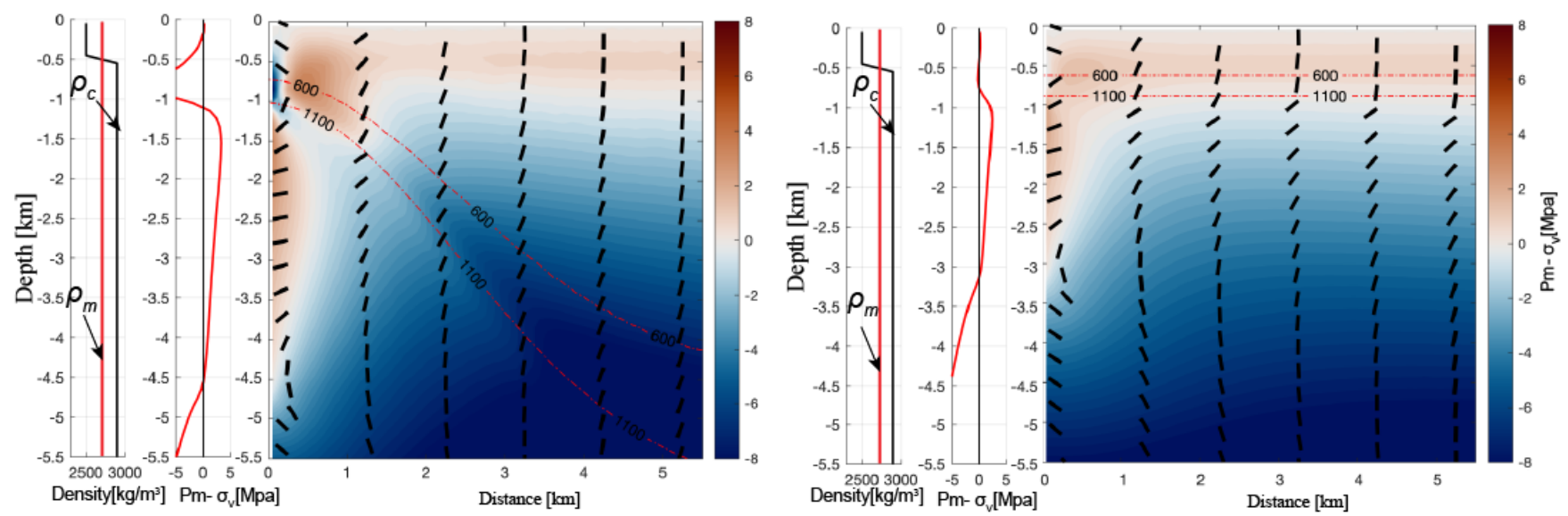

Figure S4. Case with uniform lithospheric thickness. Post-dike stresses for the standard case are shown on the left and a case with uniform lithospheric thickness with distance from the spreading axis are shown at the right. Quantites shown are defined in Figure S2. Note that the sub-lithospheric stresses favor sill opening for both cases. 


\section{(a) Topography}

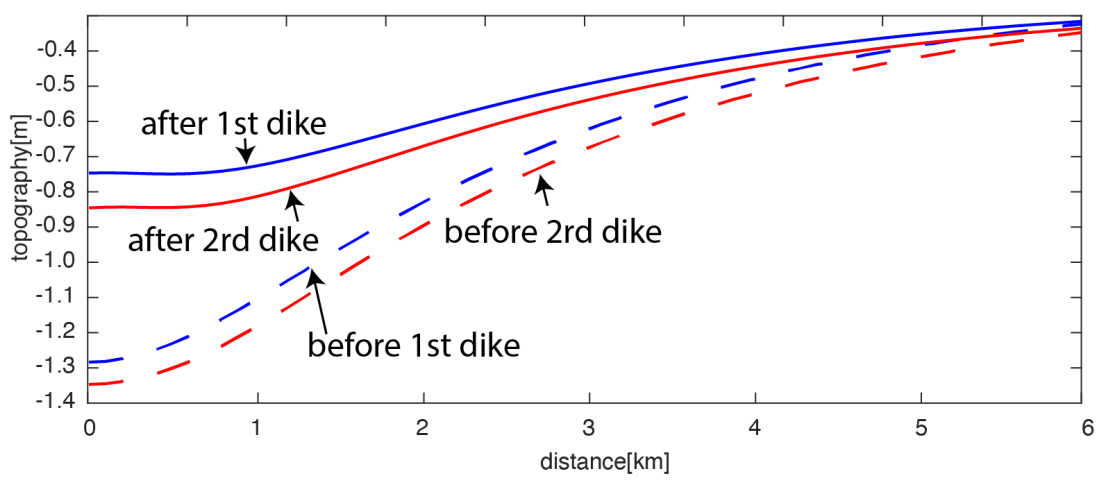

(c) Stress

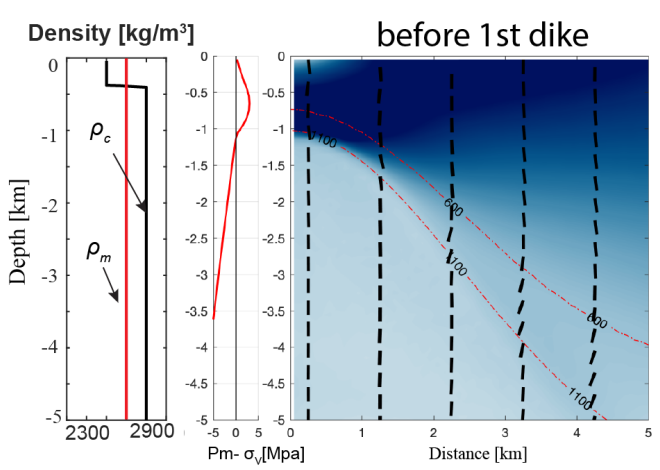

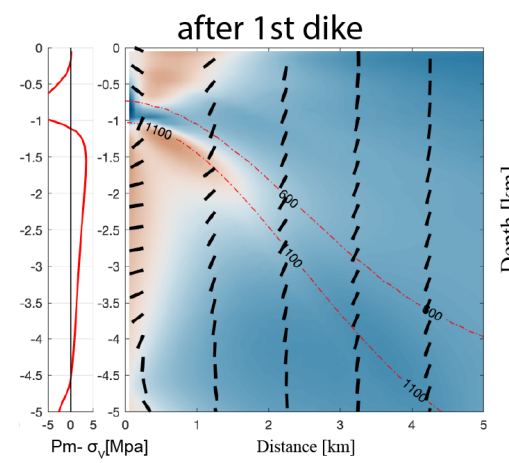

(b) dike width
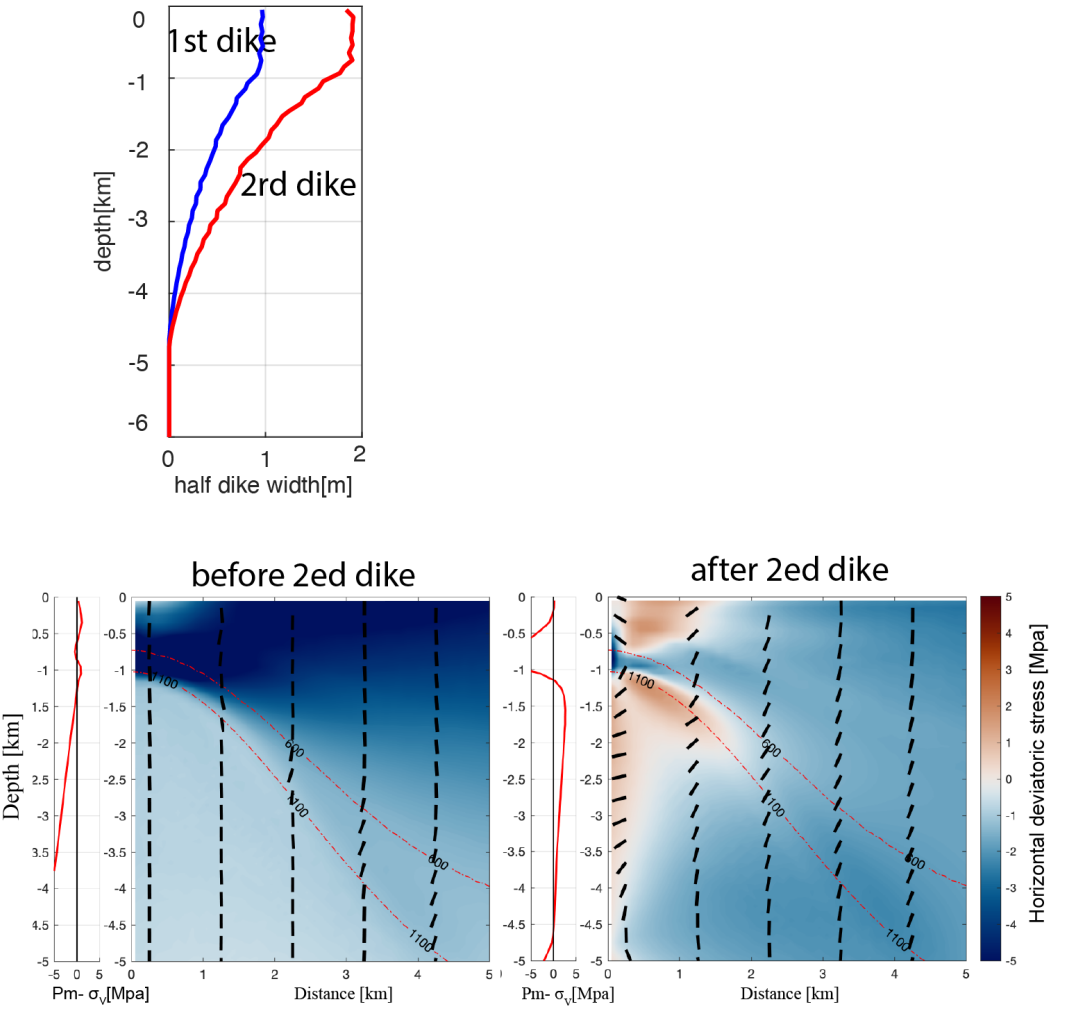

Figure S5. Model results for two loading and dike-opening periods. (a) shows surface topography and (b) show total horizontal dike opening at the spreading axis. (c) show stress changes due model run indicating that multiple dike events separated by a periond of longterm loading can still result in magma pressures that are greater than the dike induce vertical stresses. $\rho_{m}$ is the density of magma and $\rho_{c}$ is crustal density. In the panel showing the distribution of horizontal deviatoric stress, the black lines show the orientation of maximum stress and the red dashed lines represent isotherms. 